\title{
Complement Levels and Risk of Organ Involvement in Patients with Systemic Lupus Erythematosus
}

Esam M.Abu Al-Fadl ${ }^{a}$, Ahmed R. Radwan ${ }^{b}$, Abdallah E.M.Ali ${ }^{\mathrm{c}}$, Abeer H. Masoud ${ }^{\mathrm{a}}$

${ }^{a}$ Assistant Professor of Rheumatology, Faculty of Medicine, Sohag University

${ }^{\mathbf{b}}$ Lecturer of Rheumatology, Faculty of Medicine, Sohag University

${ }^{c}$ Lecturer of Clinical Pathology, Faculty of Medicine, South Valley University

\section{Abstract:}

Objectives: to estimate the effect of complement level changes on clinical manifestations, visceral damage and mortality in our patients with SLE.

Patients and method(s): A cross sectional study including 50 patients attending to South Valley University Hospitals have been included in the study for assessment of complement levels in patients with SLE and correlating complement levels with renal, neuropsychiatric, cardiac and hematological manifestations of SLE.

Result(s): The most common organ system involved was the musculoskeletal system, with arthritis in $76 \%$ of the cases. This was followed by cutaneous manifestations (72\%), then lupus nephritis (62\%), CNS lupus (44\%), hematological $(30 \%)$ and lastly CVS (12\%). Non of our cases showed liver impairment. Around two thirds of patients with renal involvement had consumed complement, compared to only $26 \%$ among those with no renal involvement; with a significant difference. It also shows that there is no significant difference between hypertension and complement level. Over $72 \%$ of patients with CNS involvement had consumed complement, compared to only $32 \%$ among those with no CNS involvement; with a significant difference. There is no significant relation between blood disorders, arthritis, mucocutaneous in lupus patients and complement consumption.

Conclusion: Our study suggested that complement consumption was strongly associated with lupus nephritis and to a lesser extent; CNS lupus, but not with other organ involvement in SLE patients.

Keywords: SLE, Complement, Organ involvement.

\section{Introduction:}

SLE is a chronic autoimmune disease characterizes by different types of autoantibodies and variable disease activity that results in multiorgan tissue damage and potentially lifethreatening complications. The incidence of SLE is variable according to many ethnic, socioeconomic and other factors, but generally is around 1-10 per 100.000 person-years with a prevalence of $20-70$ per 100000 according. It is about 6-10 times more frequent in females(Ahmadpoor et al., 2014;Scolnik et al., 2014).

The complement system is an important pathway of innate immunity and plays a major role in SLE.5 Complement participation may occur in at least two ways. First, deficiency of some complement components may be involved in the pathogenesis of disease development. In particular, complete deficiency of the complement component $\mathrm{C} 1$ has been associated with an elevated risk of SLE in up to $90 \%$ of persons with this hereditary condition. Other complement components such as $\mathrm{C} 2$ and $\mathrm{C} 4$ have also been blamed. Second, the strong activation of complement is proved to be associated with disease activity and injury to certain organs(Holers, 1999;Manderson et al., 2004).

Many complement products have been assigned different degrees of clinical value in evaluating disease activity, such as serum $\mathrm{CH} 50$, levels of C3, C4, C3d, C4d, C3a, C4a, C5b-9, $\mathrm{Ba}, \mathrm{Bb}$ and urine $\mathrm{C} 3 \mathrm{~d} .6910$.

Our objective was to estimate the effect of complement level changes on clinical manifestations, visceral damage and mortality in our patients with SLE.

\section{Patient and methods:}

Study Setting and Design: This study is a crosssectional study of 50 patients attending to South Valley University Hospitals have been included in the study for assessment of complement levels 
in patients with SLE and correlating complement levels with renal, neuropsychiatric, cardiac and hematological manifestations of SLE.

Study Population: Study population included patients attending to South Valley University Hospitals. The sample included patients of both sex and of different age.

\section{Data Collection}

All of the participants were subjected to the following:

Full history: included demographic data and personal history, detailed history of general health condition.

History of chronic medical conditions (DM, hypertension, etc).History of SLE as regards onset of the symptoms, disease duration, therapeutic history, history of major organ involvement of SLE and disease activity.

Examination: included general examination and vital signs. Systematic examinations with concentration on those suggesting renal, cardiopulmonary, neuropsychiatric or hematological complications of SLE.

Investigation :included Routine investigations (CBC with differential WBCs count), Liver functions (ALT, AST, albumin and bilirubin), Renal functions (serum creatinine, blood urea, urine analysis, urine 24 hour protein or $\mathrm{P} / \mathrm{C}$ ratio), Abdominal ultrasound, Chest $\mathrm{X}$ ray or $\mathrm{CT}$ for suspected cases of cardiopulmonary complications, Brain CT or MRI for suspected cases of neuropsychiatric cases , Immunological investigations of SLE(ANA by immunofluorescence. AntidsDNA by ELISA) and Measurement of complement level (C3/C4).

\section{Statistical Analysis}

Statistical package for social sciences (IBMSPSS) version 23 was used for statistical data analysis. Frequencies, descriptive statistics, Chi square test were done. The probability of less than 0.05 was used as cut off point for all significant tests.

\section{Results:}

Table 1. Age and duration of the study group

\begin{tabular}{|l|l|l|l|l|l|}
\hline & $\begin{array}{l}\text { Mea } \\
\text { nea }\end{array}$ & $\begin{array}{l}\text { Medi } \\
\text { an }\end{array}$ & $\begin{array}{l}\text { Std. } \\
\text { Deviation }\end{array}$ & $\begin{array}{l}\text { Min } \\
\text {. }\end{array}$ & $\begin{array}{l}\text { Max } \\
\text {. }\end{array}$ \\
\hline Age & $\begin{array}{l}28.8 \\
2\end{array}$ & 26.5 & 9.258 & 16 & 52 \\
\hline
\end{tabular}

\begin{tabular}{|l|l|l|l|l|l|}
\hline $\begin{array}{l}\text { Diseas } \\
\text { e } \\
\text { durati } \\
\text { on }\end{array}$ & \begin{tabular}{l}
3.35 \\
\hline
\end{tabular} & 2.5 & 2.84 & 0.3 & 9 \\
\hline
\end{tabular}

This table shows that the mean age of the study group ranged from 16-52 years, with a mean of 28.8 years and the mean disease duration was around 3.4 years, with a wide range from only 4 months to over 9 years, reflected in the high standard deviation of 2.8 years.

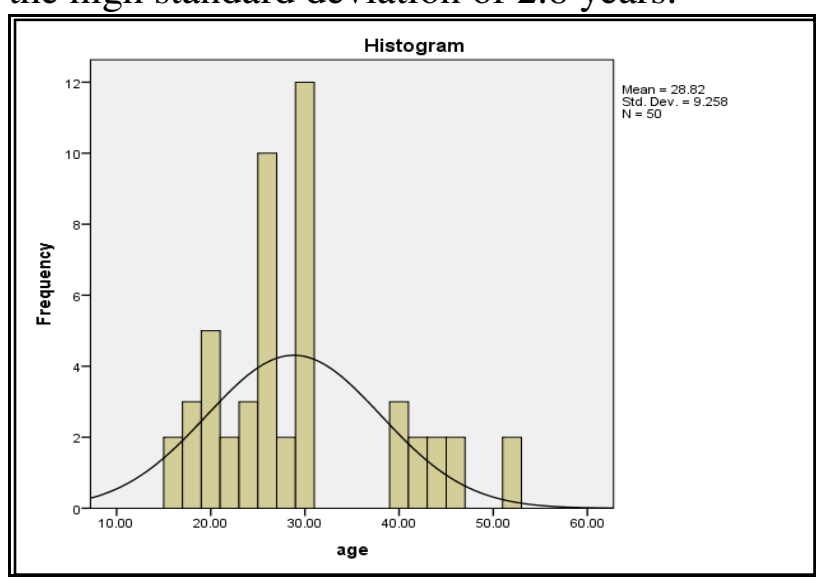

Figure 1. Age of the study group

Table 2. Sex of the study group

\begin{tabular}{|l|l|l|l|}
\hline \multicolumn{2}{|c|}{} & No & Percent \\
\hline \multirow{3}{*}{ Sex } & Male & 4 & 8.0 \\
\cline { 2 - 4 } & Female & 46 & 92.0 \\
\cline { 2 - 4 } & Total & 50 & 100.0 \\
\hline
\end{tabular}

This table shows that $92 \%$ of the cases were females, with only 4 cases $(8 \%)$ were males.

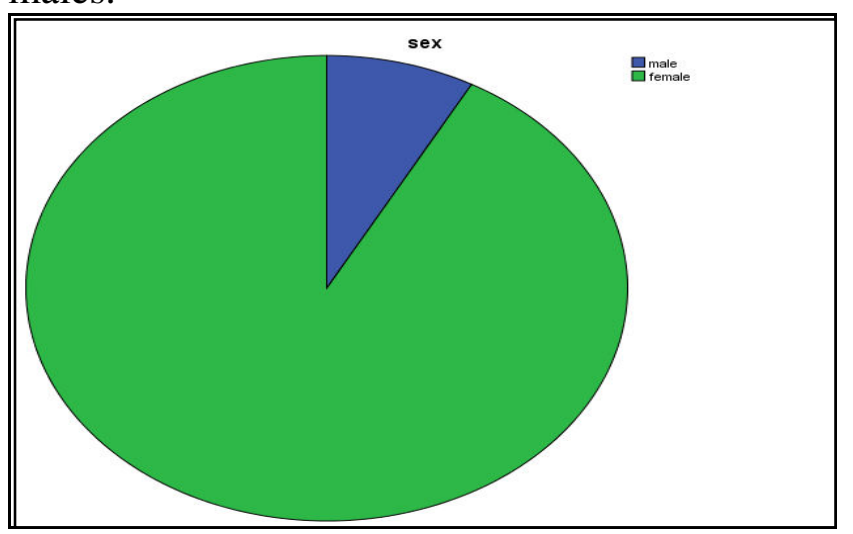

Figure 2. Sex of the study group

Table 3. Organ involvement of the study population

\begin{tabular}{|l|l|l|l|}
\hline \multicolumn{2}{|c|}{} & No & $\begin{array}{l}\text { Percen } \\
\text { t }\end{array}$ \\
\hline $\begin{array}{l}\text { Cardiovascul } \\
\text { ar }\end{array}$ & Hypertension & 6 & $12 \%$ \\
\cline { 2 - 4 } Hematologic & Pericarditis & 0 & 0 \\
\hline
\end{tabular}




\begin{tabular}{|l|l|l|l|}
\hline \multirow{2}{*}{ lupus } & Leucopenia & 11 & $22 \%$ \\
\cline { 2 - 4 } & Hemolytic anemia & 0 & 0 \\
\cline { 2 - 4 } & Allover & 15 & $30 \%$ \\
\hline Renal & Lupus nephritis & 31 & $62 \%$ \\
\hline MSK & $\begin{array}{l}\text { Neuropsychiatric } \\
\text { lupus }\end{array}$ & 22 & $44 \%$ \\
\hline $\begin{array}{l}\text { Mucocutaneo } \\
\text { us }\end{array}$ & Arthritis & 38 & $76 \%$ \\
\hline Liver & $\begin{array}{l}\text { Abnormal liver } \\
\text { functions }\end{array}$ & 0 & 0 \\
\hline
\end{tabular}

This table shows that the most common organ system involved was the musculoskeletal system, with arthritis in $76 \%$ of the cases. This was followed by cutaneous manifestations (72\%), then lupus nephritis (62\%), CNS lupus (44\%), hematological (30\%) and lastly CVS (12\%). Non of our cases showed liver impairment.

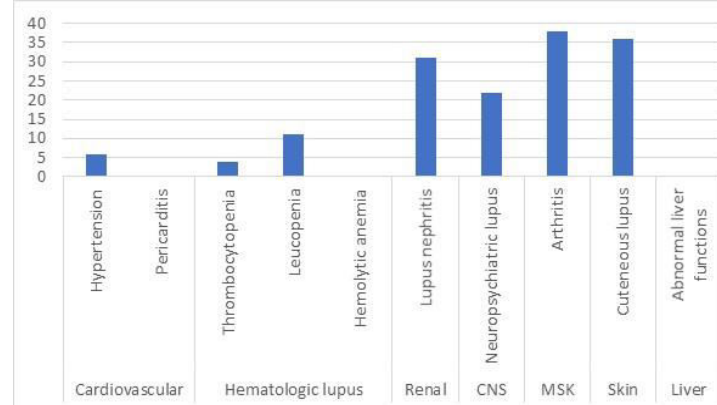

Figure 3. Organ involvement of the study population

Table 4. ANA and anti dsDNA

\begin{tabular}{|l|l|l|l|}
\hline \multicolumn{2}{|c|}{} & No & $\begin{array}{l}\text { Percen } \\
\text { t }\end{array}$ \\
\hline \multirow{2}{*}{ ANA } & Positive & 47 & $94 \%$ \\
\cline { 2 - 4 } & Negative & 3 & $6 \%$ \\
\hline \multirow{2}{*}{$\begin{array}{l}\text { Anti } \\
\text { dsDNA }\end{array}$} & Positive & 39 & $78 \%$ \\
\cline { 2 - 4 } & Negative & 11 & $22 \%$ \\
\hline
\end{tabular}

This table shows that ANA was positive in nealr all of the cases, except 3 cases (6\%), and anti dsDNA was positive in $78 \%$ of the cases.
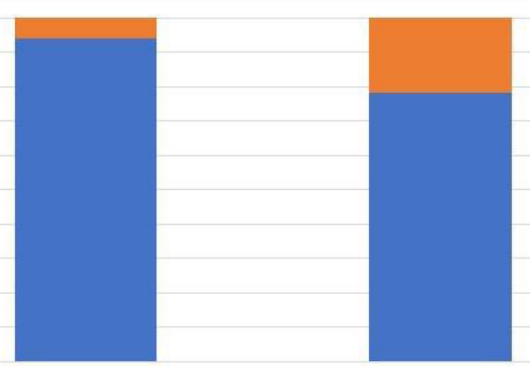

Figure 4. ANA and anti dsDNA

Table5.C3 and C4in our study population

\begin{tabular}{|l|l|l|l|l|l|}
\hline & $\begin{array}{l}\text { Mea } \\
\mathbf{n}\end{array}$ & $\begin{array}{l}\text { Media } \\
\mathbf{n}\end{array}$ & $\begin{array}{l}\text { Std. } \\
\text { Deviati } \\
\text { on }\end{array}$ & $\begin{array}{l}\text { Min } \\
\bullet\end{array}$ & $\begin{array}{l}\text { Ma } \\
\mathbf{x} .\end{array}$ \\
\hline $\begin{array}{l}\mathbf{C} \\
\mathbf{3}\end{array}$ & $\begin{array}{l}85.7 \\
9\end{array}$ & 97.50 & 43.901 & 10 & 158 \\
\hline $\mathbf{C}$ & 23.0 & 17 & 17.078 & 3 & 60 \\
$\mathbf{4}$ & 2 & & & & \\
\hline
\end{tabular}

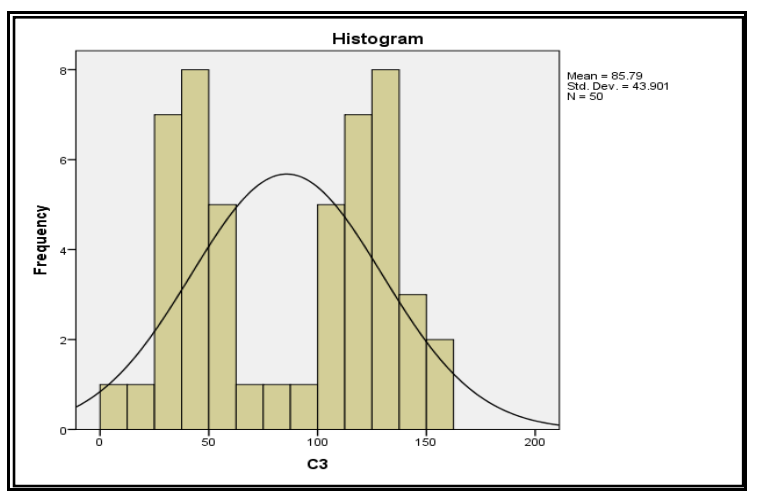

Figure 5. C3

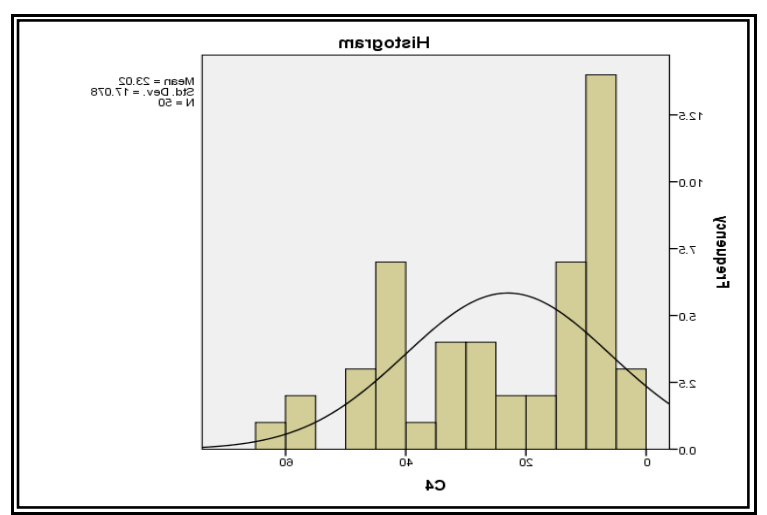

Figure 6. C4

Table 6. Complement consumption in our study population

\begin{tabular}{|l|l|l|l|}
\hline \multicolumn{2}{|c|}{} & No & $\begin{array}{l}\text { Percen } \\
\text { t }\end{array}$ \\
\hline C3 & Normal & 24 & $48 \%$ \\
\cline { 2 - 4 } & Consumed & 26 & $52 \%$ \\
\hline \multirow{2}{*}{ 44 } & Normal & 25 & $50 \%$ \\
\cline { 2 - 4 } & Consumed & 25 & $50 \%$ \\
\hline \multirow{2}{*}{$\begin{array}{c}\text { Compleme } \\
\text { nt }\end{array}$} & Normal & 25 & $50 \%$ \\
\cline { 2 - 4 } & Consumed & 25 & $50 \%$ \\
\hline
\end{tabular}

This table shows that half of our cases had complement consumption, and the other half had normal levels of both $\mathrm{C} 3$ and $\mathrm{C} 4$. 
Table 7. Complement and renal involvement and blood pressure

\begin{tabular}{|c|c|c|c|c|c|c|}
\hline & \multicolumn{4}{|c|}{ Complement } & \multirow{3}{*}{$\begin{array}{l}\text { p- } \\
\text { valu } \\
\text { e }\end{array}$} \\
\hline & & \multicolumn{2}{|c|}{ Normal } & \multicolumn{2}{|c|}{$\begin{array}{l}\text { Consume } \\
\text { d }\end{array}$} & \\
\hline & & $\begin{array}{l}\mathrm{N} \\
\mathrm{O}\end{array}$ & $\%$ & No & $\%$ & \\
\hline \multirow{2}{*}{$\begin{array}{l}\text { Renal } \\
\text { involv } \\
\text { ement }\end{array}$} & Yes & 11 & $\begin{array}{l}35 . \\
5 \%\end{array}$ & 20 & $\begin{array}{l}64.5 \\
\%\end{array}$ & \multirow{2}{*}{$\begin{array}{l}.009 \\
*\end{array}$} \\
\hline & No & 14 & $\begin{array}{l}73 . \\
7 \%\end{array}$ & 5 & $\begin{array}{l}26.3 \\
\%\end{array}$ & \\
\hline \multirow{2}{*}{$\begin{array}{l}\text { Blood } \\
\text { pressu } \\
\text { re }\end{array}$} & Normal & 20 & $\begin{array}{l}45 . \\
5 \%\end{array}$ & 24 & $\begin{array}{l}54.5 \\
\%\end{array}$ & \multirow{2}{*}{$\begin{array}{l}0.18 \\
9\end{array}$} \\
\hline & $\begin{array}{l}\text { Hyperte } \\
\text { nsion }\end{array}$ & 5 & $\begin{array}{l}83 . \\
3 \%\end{array}$ & 1 & $\begin{array}{l}16.7 \\
\%\end{array}$ & \\
\hline \multirow{2}{*}{$\begin{array}{l}\text { Blood } \\
\text { disord } \\
\text { ers }\end{array}$} & Normal & 19 & $\begin{array}{l}54 . \\
3 \%\end{array}$ & 16 & $\begin{array}{l}45.7 \\
\%\end{array}$ & \multirow{2}{*}{$\begin{array}{l}0.35 \\
5\end{array}$} \\
\hline & $\begin{array}{l}\text { Impaire } \\
\mathrm{d}\end{array}$ & 6 & $\begin{array}{l}40 \\
\%\end{array}$ & 9 & $\begin{array}{l}60 \\
\%\end{array}$ & \\
\hline \multirow{2}{*}{$\begin{array}{l}\text { CNS } \\
\text { lupus }\end{array}$} & Yes & 6 & $\begin{array}{l}27 . \\
3 \%\end{array}$ & 16 & $\begin{array}{l}72.7 \\
\%\end{array}$ & \multirow{2}{*}{$\begin{array}{l}0.00 \\
4^{*}\end{array}$} \\
\hline & No & 19 & $\begin{array}{l}67 . \\
9 \%\end{array}$ & 9 & $\begin{array}{l}32.1 \\
\%\end{array}$ & \\
\hline \multirow{2}{*}{$\begin{array}{l}\text { Arthri } \\
\text { tis }\end{array}$} & Yes & 20 & $\begin{array}{l}52 . \\
6 \% \\
\end{array}$ & 18 & $\begin{array}{l}47.4 \\
\%\end{array}$ & \multirow{2}{*}{$\begin{array}{l}0.50 \\
8\end{array}$} \\
\hline & No & 5 & $\begin{array}{l}41 . \\
7 \%\end{array}$ & 7 & $\begin{array}{l}58.3 \\
\%\end{array}$ & \\
\hline \multirow{2}{*}{$\begin{array}{l}\text { Muco } \\
\text { cutane } \\
\text { ous }\end{array}$} & Yes & 17 & $\begin{array}{l}47 . \\
2 \%\end{array}$ & 19 & $\begin{array}{l}52.8 \\
\%\end{array}$ & \multirow{2}{*}{$\begin{array}{l}0.52 \\
9\end{array}$} \\
\hline & No & 8 & $\begin{array}{l}57 . \\
1 \%\end{array}$ & 6 & $\begin{array}{l}42.9 \\
\%\end{array}$ & \\
\hline
\end{tabular}

This table shows that around two thirds of patients with renal involvement had consumed complement, compared to only $26 \%$ among those with no renal involvement; with a significant difference. It also shows that there is no significant difference between hypertension and complement level. Over $72 \%$ of patients with CNS involvement had consumed complement, compared to only $32 \%$ among those with no CNS involvement; with a significant difference. There is no significant relation between blood disorders, arthritis, mucocutaneous in lupus patients and complement consumption.

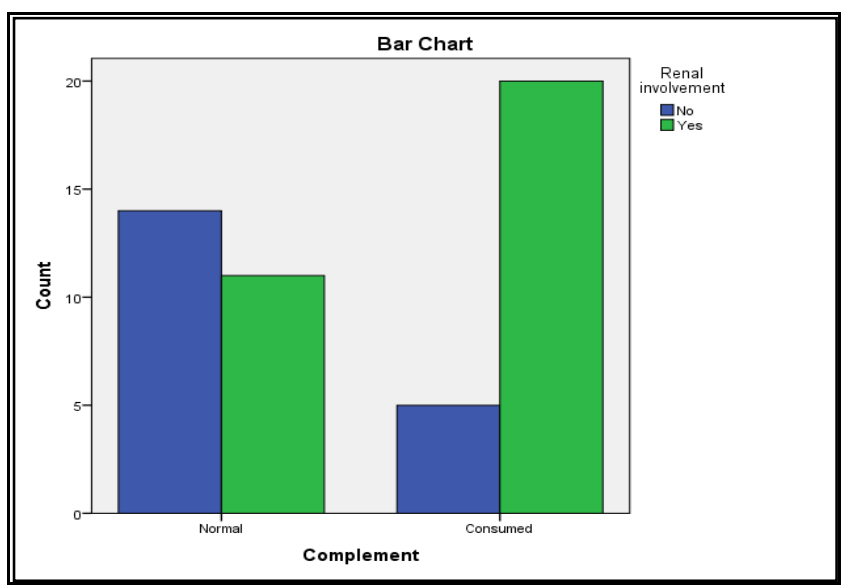

Figure 7. Complement and renal involvement

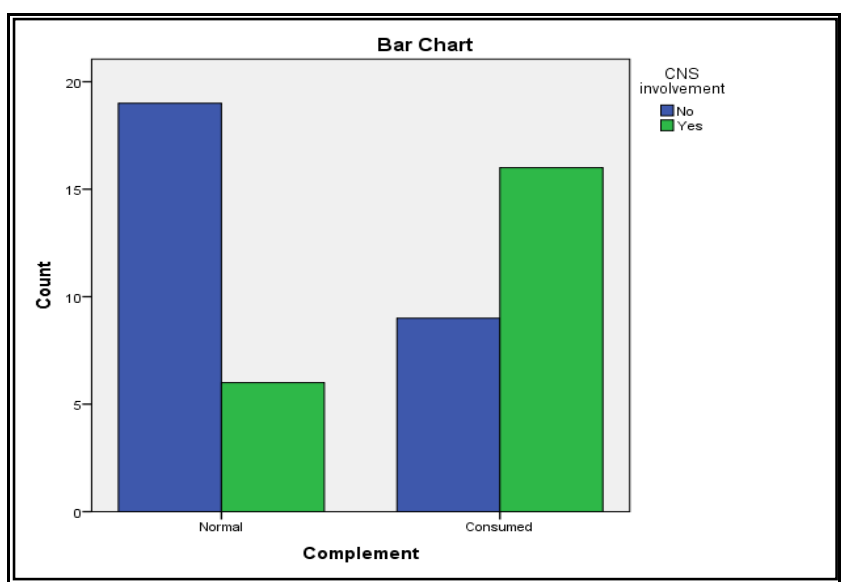

Figure 8. Complement and CNS lupus

\section{Discussion:}

SLE is a chronic autoimmune disease characterized by fluctuating disease activity, with multiorgan affection which may lead to lifethreatening outcomes(Ahmadpoor et al., 2014;Scolnik et al., 2014).

Many complement products have been assigned different degrees of clinical value in assessing disease activity, such as serum $\mathrm{CH} 50$, levels of C3, C4, C3d, C4d, C3a, C4a, C5b-9, $\mathrm{Ba}, \mathrm{Bb}$ and urine $\mathrm{C} 3 \mathrm{~d}$ (Holers, 1999).

Our objective was to estimate the impact of complement level changes on clinical manifestations, visceral injury and mortality in our patients with SLE.

The mean age of our study group ranged from 16-52 years, with a mean of 28.8 years. $92 \%$ of the cases were females, with only 4 cases $(8 \%)$ were males. The mean disease duration was around 3.4 years, with a wide range from only 4 months to over 9 years, reflected in the high standard deviation of 2.8 years. 
In study of(Gandino et al., 2017) the mean age at diagnosis was 34.2 years with SD 15.8 which older than our patients, their study included $89.6 \%$ females which was similar to ours.

The mean duration of SLE at the start of study of (Ho et al., 2001) was 11.4 years, with a range of 2-35 years which was longer than disease duration in our study.

The most common organ system involved in our study was the musculoskeletal system, with arthritis in $76 \%$ of the cases. This was followed by cutaneous manifestations (72\%), then lupus nephritis (62\%), CNS lupus (44\%), hematological (30\%) and lastly CVS (12\%). Non of our cases showed liver impairment.

In current study, ANA was positive in near all of the cases, except 3 cases (6\%), and anti dsDNA was positive in $78 \%$ of the cases, half of our cases had complement consumption, and the other half had normal levels of both C3 and C4.

Around two thirds of our patients with renal involvement had consumed complement, compared to only $26 \%$ among those with no renal involvement; with a significant difference.

Similar to our findings, (Gandino et al., 2017) found in their study that serum $C 3$ and $C 4$ were consumed in patients with renal manifestations.

Also,(Ho et al., 2001) found in their study that decrease in $\mathrm{C} 3$ or $\mathrm{C} 4$ levels was strongly associated only with concurrent renal SLE activity.

The decrease in complement at the time of renal affection maybe reflects consumption by immune complexes and deposition in tissues, particularly the kidneys (Porcel et al., 1992).

In our study, there was no significant difference between hypertension and complement level, also there is no significant relation between blood disorders in lupus patients and complement consumption.

Contrary to our findings, (Ho et al., 2001)found that significant relation between blood disorders in lupus patients and complement consumption.

Also, (Teke et al., 2017) found a significant relation between cytopenias and $\mathrm{C} 3$ and/or C4 consumption. In their study, they found that complement consumption was detected in over $53 \%$ of cases with cytopenias; compared to only $30 \%$ among those without cytopenias. The difference from our study may be due to higher number of cases in their study (221 cases). Taking individual blood components, they found that $\mathrm{C} 3$ deficiency was an independent risk factor for anemia and lymphopenia, while C4 deficiency was an independent risj factor for leucopenia. Non of them was an independent risk factor for thrombocytopenia, but C4 deficiency was an independent risk factor for "cumulative cytopenia".

Over $72 \%$ of patients in our study with CNS involvement had consumed complement, compared to only $32 \%$ among those with no CNS involvement; with a significant difference.

Our results agree with (Magro-Checa et al., 2016) who found a significantly higher prevalence of C3 and C4 among cases with neuropsychiatric lupus compared to those without neuropsychiatric manifestations $(46 \%$ versus $26 \%$; respectively for C3 deficiency, and $33 \%$ versus 24\%; respectively for C4 deficiency). Also, they found that diffuse neuropsychiatric manifestations were associated with more complement deficiency prevalence than focal neuropsychiatric manifestations $(65 \%$ versus 38\%; respectively for C3 deficiency, and $53 \%$ versus $22 \%$ for C4 deficiency).

We found also that there is no significant relation between arthritis, mucocutaneous manifestations lupus patients and complement consumption.

(Petri et al., 2012) did not find an association between complement consumption and organ damage. The strongest predictors of damage in their study appeared to be age and current corticosteroid dose.

In study of (Gandino et al., 2017), the 10year survival rate was about $90 \%$ which like other series (Kasitanon et al., 2006), and according to their results, complement behavior did not seem to influence survival(Gandino et al., 2017).

Some studies have suggested that the terminal attack complex is more sensitive than C3 or C4 in measuring SLE (Porcel et al., 1995). However, results from other studies have shown that the terminal attack complex correlated poorly with SLE disease activity (Manzi et al., 1996). 
Other studies measuring complement activation products allow for a different, albeit, controversial, approach to monitoring lupus disease activity. Elevated levels suggest that SLE (or other diseases in question) is active, while low levels indicate that consumption is greater than synthesis (Walport, 2002).

Unfortunately, direct measurement of complement activation products is not routinely accessible, is short-lived and may also be influenced by activation during the procurement and freeze thawing. Newer data, however, has identified serum cell-bound complement activation products (CB-CAPS) with half-lives as long as the hematopoietic cells with which C3d and C4d (erythrocytes EC4d, B-type lymphocytes BC4d) are bound (Liu et al., 2010).

These CB-CAPS are identified in most patients with SLE and have demonstrated greater specificity and sensitivity compared to using low serum complements for the diagnosis of lupus(Kalunian et al., 2012).

Similar studies have demonstrated that elevated levels of complement split products, particularly those of the alternative and terminal pathway activation, may more accurately reflect disease activity than conventional monitoring of complement $\mathrm{C} 3$ and $\mathrm{C} 4$ in predicting an impending SLE flare (Buyon et al., 1992, Cavallo 1994).

More studies are indicated to clarify this concept and are ongoing with CB-CAPS demonstrated to be fairly specific $(80-90 \%)$ for and present even in mild SLE (Liu et al., 2010; Kalunian et al., 2012).

\section{Conclusion:}

Our study suggested that complement consumption was strongly associated with lupus nephritis and to a lesser extent; CNS lupus, but not with other organ involvement in SLE patients.

\section{References}

Aguila LA, Lopes MR, FZ, PD, SampaioBarros, Carlos de Souza FH, BorbaEF.et al.,(2014).Clinical and laboratory features of overlap syndromes of idiopathic inflammatory myopathies associated with systemic lupus erythematosus, systemic sclerosis, or rheumatoid arthritis.ClinRheumatol, 33(8): 1093-1098.

Ahearn JM, Fearon DT.(1989).Structure and function of the complement receptors, CR1 (CD35) and CR2 (CD21).AdvImmunol, 46: 183219.

Ahmadpoor P, DaliliN,RostamiM. (2014).An update on pathogenesis of systemic lupus erythematosus. Iran J Kidney Dis., 8(3):171-184.

Akhavan PS, SuJ,Lou W,Gladman DD, Urowitz MB, FortinPR. (2013). The early protective effect of hydroxychloroquine on the risk of cumulative damage in patients with systemic lupus erythematosus. J Rheumatol, 40(6):831-841.

Al Saleh J, El Sayed V. Jassim N, Mohammed Khan N. (2008). Hypothyroidism determines the clinical and immunological manifestations of Arabs with lupus. Lupus, 17(3): 215-220.

Albrecht EA, ChinnaiyanAM,Varambally S, Kumar-SinhaC, BarretteTR, Sarma JV et al., (2004).C5a-induced gene expression in human umbilical vein endothelial cells.Am J Pathol, 164(3):849-859.

Aleem A, Al-SugairS. (2006).Thrombotic thrombocytopenic purpura associated with systemic lupus erythematosus.ActaHaematol, 115(1-2):68-73.

Altorok N,SawalhaAH.(2013). Epigenetics in the pathogenesis of systemic lupus erythematosus.CurrOpinRheumatol, 25(5):569576.

Andonopoulos, AP. (1991). Adult respiratory distress syndrome: an unrecognized premortem event in systemic lupus erythematosus. $\mathrm{Br} \mathrm{J}$ Rheumatol, 30(5):346-348.

Andrejevic S, JeremicI, SefikBukilicaM,Nikolic M, StojimirovicB,BonaciNikolicB. (2013).Immunoserological parameters in SLE: high-avidity anti-dsDNA detected by ELISA are the most closely associated with the disease activity.ClinRheumatol, 32(11): 16191626.

AppelGB, ContrerasG, DooleyMA, Ginzler EM,Isenberg D,Jayne D et al., (2009).Mycophenolatemofetil versus cyclophosphamide for induction treatment of lupus nephritis.J Am SocNephrol, 20(5):11031112.

Aringer M, CostenbaderK, Daikh D, Brinks R, Mosca M, Ramsey-Goldman $R$ et al., 
(2019).2019 European League Against Rheumatism/American College of Rheumatology classification criteria for systemic lupus erythematosus. Ann Rheum Dis, 78(9): 1151-1159.

Aringer M, Fischer-Betz R,Hiepe F,KommissionPharmakotherapie der D. (2013).Statement on the use of mycophenolatemofetil for systemic lupus erythematosus. Z Rheumatol, 72(6):575-580.

Asherson RA, Higenbottam TW,DinhXuan AT,Khamashta MA, Hughes GR. (1990).Pulmonary hypertension in a lupus clinic: experience with twenty-four patients. J Rheumatol, 17(10):1292-1298.

Asherson RA, OakleyCM. (1986).Pulmonary hypertension and systemic lupus erythematosus. J Rheumatol, 13(1):1-5.

Atkinson JP, Goodship TH. (2007).Complement factor $H$ and the hemolytic uremic syndrome. J Exp Med, 204(6): 12451248.
Austen WG, JrKyriakides C, Favuzza J, WangY, KobzikL, MooreFD, Jr. et al., (1999).Intestinal ischemia-reperfusion injury is mediated by the membrane attack complex. Surgery, 126(2):343-348.

Banz Y,RiebenR. (2012).Role of complement and perspectives for intervention in ischemiareperfusion damage. Ann Med, 44(3):205-217.

Belmont HM. (2013).Treatment of systemic lupus erythematosus - 2013 update. Bull HospJt Dis, 71(3):208-213.

Benseler SM, SilvermanED. (2007). Neuropsychiatric involvement in pediatric systemic lupus erythematosus. Lupus, 16(8):564571.

Bernatsky S, Ramsey-Goldman R, Rajan R, BoivinJF, JosephL, Lachance $S$ et al., (2005).Non-Hodgkin's lymphoma in systemic lupus erythematosus. Ann Rheum Dis, 64(10):1507-1509. 